\title{
A World Federation of Institutes of Advanced Study
}

\author{
A B D US SALA M
}

Director, International Centre for Theoretical Physics-Trieste

A number of groups have been working independently towards the project of setting up one or more world universities. That this is of importance in the context of the international future of mankind goes without saying. That at least one university did not come into existence at the same time as the United Nations organization did in 1945 is something of which the world's academic community cannot feel proud. Recognising this, at its twenty-fourth session, in 1969, the General Assembly of the United Nations adopted the resolution 2573 (XXIV) inviting the Secretary-General to undertake a comprehensive expert study on the feasibility of an international university. In introducing this widely sponsored resolution, it was stated that "the establishment of an international university would satisfy the aspirations which were becoming apparent in all parts of the world and it would fulfil an obvious need".

There are at least four reasons for this universal interest in the setting up of one or more international world universities :

1. The idealistic reason-international understanding

There is no instrument more potent in bringing an appreciation of different-at present national-points of view than the atmosphere of an international university.

2. Global studies

Within the context of such a university there is the possibility of growth of international studies on global subjects - -like international development, international economics, global environment, disarmament and the like.

3. Contacts of scholars

Human knowledge transcends national boundaries. To a scholar interested even in his narrow speciality, there is nothing more valuable than the possibility of free contact with his peers from all countries. A wellconstituted world university may resolve the present political difficulties in achieving such contacts.

$2-12550$ 
4. Access to specialized knowledge far scholars from developing countries

In the past, when scholars and scientists have worried about international contacts, they have tended to feel concern about East and West contacts only. One tends to forget the needs for contact of students and scholars from developing countries with their peers from developed countries. Opportunities for such contacts do not exist-not for political reasons, but because of economic factors. A world university, representing East, West and the third world, is less likely to forget the needs of these students and scholars and more likely to afford them access to academic, scientific and technical areas at present the exclusive preserve of the richer countries. The developing countries fully recognize that a truly international university - preferably under the UN auspices-is the one real guarantee for their scholars to receive their share-as of right-of the facilities and resources of the international institutions to be created.

In response to the General Assembly resolution a study has been carried out on behalf of the Secretary-General. This study suggests the setting up of a set of postgraduate international institutions within the United Nations family-to be called UN International Universities-with two objectives :

(a) "To enable scholars from all parts of the world jointly to study research and reflect on the principles, moral imperatives, objectives, purposes, perspectives and needs of the UN system in the light of its fundamental laws and developing accords, declarations, resolutions and programmes".

(b) "Secondly, to undertake a continuing and widely-based international scholarly effort of study and research, directed in consonance with Charter obligations towards social, economic and cultural progress through co-operation among nations and peoples. The universities would achieve these ends through emphasizing......... relevant international studies, largely inter-disciplinary, of wide and generally global significance".

It is clear that the objectives of this particular response to the General Assembly resolution are limited to the special global studies related to global problems. This is not going to be a traditional university pursuing the traditional range of subjects, but a specialized institute or set of institutes.

Commendable as this response is, it falls short of the aspirations of at least two of the communities which have supported world university projects. By 
and large both these communities have had in mind the traditional range of academic disciplines, in addition to global studies. The two communities are :

(i) Academic scholars and scientists in East and West who desire in their traditional disciplines more contacts with each other.

(ii) Developing countries who look upon the world university idea as the one way by which they can secure entry for their students and scholars into the privileged intellectual, scientific and technological club on terms of equality. Notwithstanding the fact that no stated bar operates against anyone from a developing country pursuing advanced studies and research at any of the world's great institutes, in practice the economic and other factors do operate in such a manner that at least the scientific and technological gap between the poor and the rich countries grows ever wider. The developing countries look upon the world university project as a means to bridge this gap.

From this it would seem that nothing short of one or more full-fledged world universities in traditional disciplines - at least for post-graduate scientific and technological studies-will satisfy these two groups.

Unfortunately, to develop full fledged universities-and particularly under UN sponsorship - is not all that easy. One does not have to recount the diffculties which are likely to be met. Since the sums of money involved are large, it is out oî the question that the United Nations Organization-even with the generous support of the World Bank-could finance such a venture. It is also unclear if one could get a number of the richer countries passionately interested in a project of this type and ready to back it. There are too many casualties among proposed international or regional institutions in the academic field already to give one great hopes of success, unless one proceeded in a gradual manner. Further, the choice of location of such a world university in one country in preference to another will always present difficulties. Even the choice of faculties to develop first is not going to be all that plain sailing.

One way to circumvent the difficulty of creating new institutes, and yet to achieve at least partly some of the objectives listed above, is to take advantage of existing centres of excellence and quality which would like to discharge international functions and to link such centres with the UN institutions for global studies proposed by the Secretary General, the whole making up the beginning of a world university.

This note then is concerned with a world university idea emerging gradually from an amalgam of the UN institutes together with existing centres of advanced studies linked in a federation. In the first instance the emphasis is on postgraduate research and training for research. Later development of the idea may envisage undergraduate studies and the corresponding institutions. 
Let us consider the various stages of the post-graduate plan. The important point we wish to make is that every part of the plan has merits of its own, irrespective of whether the later stages follow or not. The first stage is the identification of such existing institutions which already operate substantial international programmes. There is around the world no dearth of institutions of quality which are to a lesser or larger degree international in character, even though their original charters do not specify this. The idea would be to make them even more consciously so. The hope is that a voluntary federation would help in this: at the least in defining norms and making it possible to share experiences; at the best in raising new funds for the international operation. As a second part of the plan, and if this federation so chooses, a UN charter could be accepted and a formal link established with the UN Institution on Global Problems proposed by the Secretary-General. The centres constituting the federation and covering traditional disciplines together with the Secretary-General's UN University on Global Problem.s, would make a complementary whole-the beginning of a world university.

Such centres as should belong to the proposed federation must satisfy certain criteria. For example, such centres must possess the highest rating of quality ; they must possess - to a lesser or greater degree-an international faculty of staff and research fellows; they must agree to spend a minimum proportion (to be fixed, perhaps between $15 \%-25 \%$ ) of their resources and their facilities towards furthering the work of high-grade scholars from developing countries.

To illustrate the working of one such centre, one may perhaps cite the example of the International Centre for Theoretical Physics at Trieste, Italy. This case is not typical because the institute is financed and run by two of the United Nations Agencies, but it does provide an example of the type of international academic faculty in actual operation. The centre was set up under the auspices of the International Atomic Energy Agency (IAEA) with the co-operation (and from 1970 equal participation) of the United Nations Educational Scientific and Cultural Organization (UNESCO). The centre is devoted to imparting training for and conducting research in all disciplines of theoretical physics at the highest level. It draws its scientific faculty (consisting mainly of visitors) and research fellows from (theoretically 100 but in practice) some 50 countries of the East, West and the third. world. Some 50\% of its facilities and junior and senior research positions are reserved for scientists from developing countries. A unique feature is that the Centre offers dual appointments to active senior theoretical physicists from developing countries. Such appointments are held for periods of three to five years; the scholar spends the bulk of his time-about nine months of the year-in his own country, and the remaining three months of every year in Trieste. In addition, the Centre has built up federation links with some twenty research institutes in various countries-on 
a cost-sharing basis-which afford mobility of their staffs and research fellows. On the East-West co-operation side, as a UN-sponsored organization, the centre plays an absolutely unique role : it is one of the few places in the wcrld where physicists in subjects as sensitive as plasma research from the East and West meet regularly and for prolonged periods (quarters or years) and with no national pride or sensitivities inhibiting scientific concourse.

The proposed World Federation of International Institutes of Advanced Study would include centres with already a large international programme or desirous of starting one. The institutes which would join this federation may operate schemes of dual appointments and federation with corresponding centres both in developed and developing countries. From informal contacts one knows that a number of institutes in USA, USSR, Great Britain, France and other countries are extremely desirous of widening their faculties internationally to share staffs and visitors with others in the same disciplines and, through the strength given to their international programmes by the fact of belonging to such a federation, be obliged to throw their doors even more widely open to scholars from developing countries.

Why should a federation be created of institutes in diverse subjects ? What advantages could come to the members of the proposed federation ? Should it be independent institutes as well as institutes within national universities which should be invited to join? What about the financing of the international programmes? And the links to the UN family?

In answering these questions, one has to ask if the federation could te stronger in any way in carrying out the international aspects of its programmes than any one of its component units ? Would, for example, the Trieste Centre get any benefit by being federated in a sort of loose link with the Institute for Advanced Study at Princeton, or the Salk Institute for Biological Studies ?

In our opinion, the answer to the last question is an affirmative "yes". The fact that a federation exists is likely to have important repercussions :

1. To get the general idea of international staffs and international use of facilities of scientific institutes accepted in a more "official " manner by the governing bodies of the institutes.

2. To secure a mobility of high grade scientific personnel. Hopefully, there may emerge a UN Laissez Passer for academic personnel to travel freely, at least between the federating institutes, if the UN did get involved with the federation idea.

3. A commitment in respect of scholars from developing countries: a federation to which a fair number of reputable institutions belong would go much further in organizing and getting accepted common standards. 
The committing of a certain percentage of resources to helping scholars from developing countries, and to scholars from countries with different political systems, is a new idea. Many institutes do set aside certain sums but there is no coherent policy about this. We are hoping that belonging to a federation would provide a visibility to these efforts and a better focus.

4. If we envisage that institutes from developing countries would also belong to such a federation, these institutes will in many cases have to raise their standards in order to qualify to join. This type of pressure would be an excellent tonic for them, and make the tasks of those running theșe institutes vis-a-vis their own governing councils-and their Governments-somewhat easier.

5. In respect of the question raised, whether it should be independent institutes which should federate or those located within universities, one should keep an open mind. In every case the permission of the governing bodies of the institutes would be needed. I believe this is easier for independent institutions. For the present we may envisage only such institutes being invited, but the matter should be dealt with pragmatically.

6. The question of financing international programmes is a difficult one. It is definitely envisaged that in the first instance the members of the federation would find funds from their own sources for this. Later, collective action may bring extra funding from outside-even from UN sources.

7. A first list of possible independent or semi-independent institutes which may consider forming initial membership of the federation is suggested in the Appandix. It is suggested that a preliminary meeting of Directors of these institutes be held to gain acceptance of the ideas in this note.

Some of the large private and semi-private institutes-and possibly also some of the university departments-may join as Associate Members of the Federation. For example :

1. CERN-Theory Division and Electronics (Technology) Division;

2. Oak Ridge Laboratory-Life Sciences Division;

3. Centre d'Etudes Nucleaires de Saclay-Solid State Division;

4. Philips Research Laboratory, Eindhoven (Director: Dr. G. W. Rathenau).

Note added November 1972

This memorandum was circulated in 1970 in a mimeographed form. The late Professor Arné Tiselius, President of the Nobel Foundation took up the ideas and at two Serbelloni meetings held during 1971 and early 1972, the idea of an International Federation of Institutes of Advanced Study was hammered out. 
This Federation, consisting at present of 24 Institutes, was inaugurated at a meeting at Trieste during October 1972. Its offices are located in the Nobel Foundation House, Stockholm. Its Chairman is Nils Stähle and its Secretary is Sam Nisson.

The Federation may become the precursor of a World University. 


\section{Appendix of Pure Science}

1. International Centre for Theoretical Physics

Trieste, Italy.

2. International Institute of Mathematics

Warwick

(Director : Prof. E. C. Zeeman)
8. Institute for. Advanced Study Princeton, New Jersey, USA (Director: Prof. C. Kaysen)

9. Salk Jnstitute for Biological Studies

San Diego, Calif., USA

(President : Dr. J. E. Slater)

10. Instituts Internationaux de Physique et de Chimie, Solvay Brussels, Belgium

(Director : Prof. 1. Prigogine)

11. Tata Institute of Fundamental Research

Bombay, India.

(Director: Prof. M. G. K. Menon).

5. Weizmann Institute of Science Rehovoth, Israel (President: Prof. A. Sabin)

6. Niels Bohr Institute Copenhagen, Denmark (Director : Prof. A. Bohr)

7. Institute for Advanced Scientific Studies

Paris, France

(Director : Prof. L. Motchane)
12. Institute for Physical Problems USSR Academy of Sciences Moscow, USSR

(Director : Academician P. L. Kapitza).

13. Mathematical Institute of the Academy of Sciences of the USSR Moscow, USSR

(Director : Academician I. M. Vinogradow). 
14. Institute for Theoretical Physics of the Academy of Sciences of the Ukrainian SSR

Kiev, USSR

(Director : Academician N. N. Bogolubov

(Deputy Director : V. Shelest).

15. Institute for Nuclear Physics Novosibirsk, USSR

(Director : Academician A. H. Budker).

16. Institut Pasteur

Paris, France

(Director : Prof. Pierre Mercier)

17. Max Planck Society for the Advancement of Science

Munich, Fed. Rep. Germany.

18. The Institute of Immunology Basle, Switzerland.

19. Cold Spring Harbor Laboratory of Quantitative Biology

New York, USA

20. Institute of Hydrobiology

Lago Maggiore, Italy

21. Foundation J. Oswaldo Cruz, Brazil.
22. Institute of Mathematics of the Polish Academy of Sciences

Warsaw, Poland

23. Institute for Fundamental Technical Problems

Warsaw, Poland

24. Medical Research Council National Institute for Medical Research Mill Hill, London N.W. 7 England

(Director Sir Peter Medawar)

25. Division of Radio Physics Commonwealth Science and Industrial Research Organisation

Sydney, Australia

(Director: Dr. E. G. Bowen)

26. Walter and Eliza Hall Institute for Medical Research Royal Melbourne Hospital

Melbourne, Australia

(Director: Prof. G. J. V. Nossal)

27. Institute of Biophysics

Avenida Pasteur 458

Rio de Janeiro

(Director : Prof. Carlos Chagas)

28. Mathematical Centre

49, 2e Boerhaavestraat

Amsterdam, The Netherlands 


\section{Appendix for Technology and Applied Science}

1. Woods Hole Oceanographic Institution

Woods Hole, Mass., USA

(Director: Prof. Paul M. Fye)

2. Worcester Foundation for Experimental Biology

Shrewsbury, Mass., USA

3. Sloan-Kettering Institute for Cancer Research

New York, N. Y., USA

4. International Rice Research Institute

Manila, Philippines

(Director : Dr. R. F. Chandler, Jr.)

5. International Maize and Wheat Improvement Centre

Mexico

(Director: Dr. Norman E. Borlaug)

6 Asian Institute of Technology Bangkok, Thailand

(Director: Milton E. Bender, Jr.)

7. Iron and Steel Institute of Japan Tokyo, Japan

(President: Ichiro Fujimoto)

8. Institut Francais du Petrole, des Carburants et Lubrifiants

Paris, France

(President and General

Manager : R. Navarre)
9. M. Nencki Institute of Experimental Biology

Warsaw, Poland,

(Director: Prof. J. Konorski)

10. Carlsberg Foundation

Institute for Fermentation

Copenhagen, Denmark

(Fermentation Studies)

11. International Centre for Seismology

Edinburgh, Scotland

12. Institute of Geology

Delft, Holland

13. Japan Institute of Metals Sendai, Japan.

(President: Prof. Yonoshin Imai)

14. (Proposed) Institute on Insect Physiology

Nairobi, Kenya

15. Rothampsted Experimental Station (Agricultural)

Harpenden, Herts., England

(Director: Sir Federick Bawden)

16. International Centre for Advanced Technical and Vocational Training Turin, Italy

17. Batelle Memorial Institute Geneva, Switzerland

(Director : M. Thiemann) 
18. Cancer Institute Lyon, France

19. Stanford Research Institute Menlo Park, Calif., 94025 (President: Charles A. Anderson).
20. German-French Reactor Tnst., Grenoble, France.

21. Pakistan Institute for Nuclear Science \& Technology Islamabad, Pakistan.

\section{Appendix for Social Science}

1. UNITAR (United Nations)

2. Centre for Advanced Study in Behavioral Sciences Stanford, Calif., USA (Dr. O. Meredith Wilson)

3. Economic Development Institute of the World Bank Washington, D.C., USA

4. United Nations Research Institute for Social Development

Geneva, Switzerland.
5. Centre for Cultural and Technical Interchange between East \& West

Honolulu, Hawai, USA

(Chancellor : Everett Kleinjans)

6. European Institute for Advanced International Studies Nice, France

(Director : Alexander Marc)

7. Peace Research Institute Stockholm, Sweden

(Director: Dr. R. R. Neild)

8. The John F. Kennedy School of

Government

Harvard University

Cambridge, Mass., USA

(Dr. Don K. Price) 